La Revue

des Droits

de l'Homme

\section{La Revue des droits de l'homme}

Revue du Centre de recherches et d'études sur les droits fondamentaux

Actualités Droits-Libertés | 2008

\title{
Port de signes religieux et documents officiels
}

Liberté de religion (Art. 9 CEDH)

\section{Nicolas Hervieu}

\section{(2) OpenEdition}

\section{Journals}

Édition électronique

URL : http://journals.openedition.org/revdh/3550

DOI : $10.4000 /$ revdh.3550

ISSN : 2264-179X

\section{Éditeur}

Centre de recherches et d'études sur les droits fondamentaux

\section{Référence électronique}

Nicolas Hervieu, «Port de signes religieux et documents officiels », La Revue des droits de l'homme [En ligne], Actualités Droits-Libertés, mis en ligne le 28 novembre 2008, consulté le 19 avril 2019. URL : http://journals.openedition.org/revdh/3550 ; DOI : 10.4000/revdh.3550

Ce document a été généré automatiquement le 19 avril 2019

Tous droits réservés 


\title{
Port de signes religieux et documents officiels
}

\author{
Liberté de religion (Art. 9 CEDH)
}

Nicolas Hervieu

1 La Cour européenne des droits de l'homme a rendu le 27 novembre 2008 une décision d'irrecevabilité opposée à une requête qui visait la France (Shingara Mann Singh c. France , Cinquième Section, 13 novembre 2008, requête $n^{\circ} 24479 / 07$ ) mettant ainsi le point final à un célèbre et récent contentieux dont le Conseil d'Etat avait eu à connaître.

2 Une personne de confession sikh s'est vu refuser par l'administration française la délivrance d'un duplicata de son permis de conduire au motif qu'il portait un turban sur les photos d'identité qu'il fournissait à cette fin. L'intéressé fit valoir que le port permanent de ce turban est une exigence religieuse et que le refus de l'administration violait notamment son droit à la libre manifestation de ses convictions religieuse. Divers recours furent formulés sans succès devant les juridictions administratives françaises (dont le Conseil d'Etat - CE, 5ème et 4ème sous-sections réunies, 15 décembre 2006, Association United Sikhs, requête $n^{\circ}$ 289946).

3 La Cour, saisie d'une requête arguant notamment d'une violation de l'article 9 (liberté de pensée, de conscience et de religion), rappelle tout d'abord les principes protecteurs de la liberté religieuse et en souligne ses limites ( L'article 9 ne protège pas n'importe quel acte motivé ou inspiré par une religion ou conviction [...]. De plus, il ne garantit pas toujours le droit de se comporter d'une manière dictée par une conviction religieuse et ne confere pas aux individus agissant de la sorte le droit de se soustraire à des règles qui se sont révélées justifiées ". L'arrêt Leyla Sahin c. Turquie - Grande Chambre, 10 novembre 2005, requête $n^{\circ} 44774 / 98$ - est abondamment cité à l'appui de ces éléments). La juridiction strasbourgeoise mentionne ensuite plusieurs décisions d'irrecevabilité par lesquelles les restrictions apportées au port de signes religieux - tout particulièrement de couvre-chefs comme le turban ou le voile - furent considérées comme justifiées par des considérations de sécurité ou de santé. 
4 Dans l'affaire d'espèce, le juge s'inscrit pleinement dans le droit fil de ces solutions. Il relève ainsi que l'interdiction du port du turban sur la photo de son permis de conduire répondaient à des exigences de sécurité publique, notamment de lutte contre la fraude et la falsification de documents officiels. De plus, la Cour estime que «les modalités de la mise en cuvre de tels contrôles entrent dans la marge d'appréciation de l'Etat défendeur, et ce d'autant plus que l'obligation de retirer son turban à cette fin ou, initialement, pour faire établir le permis de conduire, est une mesure ponctuelle ». Enfin, le fait que le requérant ait été, par le passé, autorisé à fournir des photographies où il était coiffé du turban n'est pas jugé par la Cour comme étant de nature à contredire cette appréciation. Dès lors, la Cour «conclut que l'ingérence litigieuse était justifiée dans son principe et proportionnée à l'objectif visé » et rejette la requête comme irrecevable.

5 Sans véritable surprise, la Cour entérine donc ici la position du Conseil d'Etat français qui avait été également conduit à répondre au requérant sur le terrain de l'article 9.

Cour EDH, 5e Sect. 13 novembre 2008, Shingara Mann Singh c. France, Req. $\mathbf{n}^{\mathrm{o}}$ 24479/0713

\section{AUTEUR}

NICOLAS HERVIEU

CREDOF - Université de Paris Ouest Nanterre la Défense 